\title{
SERVICE INNOVATION MANAGEMENT PRACTICES AND PRICING PRACTICES FOR PERFORMANCE IN MALAYSIAN TELECOM
}

\author{
Seyedeh Khadijeh Taghizadeh ${ }^{1 *}$, K. Jayaraman², Syed Abidur Rahman ${ }^{1}$, \\ and Ali Quazi ${ }^{3}$ \\ ${ }^{1}$ OYA Graduate School of Business, Universiti Utara Malaysia, 01060 UUM, \\ Sintok, Kedah, Malaysia \\ ${ }^{2}$ Taylor's Business School (TBS), Taylor's University, No. 1, Jalan Taylor's, \\ 47500 Subang Jaya, Selangor, Malaysia \\ ${ }^{3}$ School of Management, Faculty of Business, Government and Law, \\ University of Canberra, Canberra, Australia \\ *Corresponding author: taghizadeh.nastaran@gmail.com
}

Published online: 29 December 2017

To cite this article: Taghizadeh, S.K., Jayaraman, K., Rahman, S.A., and Quazi, A. (2017). Service innovation management practices and pricing practices for performance in Malaysian telecom. Asian Academy of Management Journal, 22(2), 129-155. https://doi. org/10.21315/aamj2017.22.2.5

To link to this article: https://doi.org/10.21315/aamj2017.22.2.5

\begin{abstract}
This study aims to test the role of pricing practices as an intervening variable in the relationship between service innovation management practices (innovation strategy, innovation process, cross-functional organisation, tools/technology, and system integration) and firms' performance in an emerging economy. Data were collected from 249 managers representing the Malaysian telecommunications sector using a structured questionnaire. Structural equation modelling (SEM) with SmartPLS software, version 3, was used to achieve the research objectives and to analyse the measurements and structural model. The results showed that, whereas innovation strategy, innovation process, cross-functional organisation, and system integration positively influence pricing practice, tools and technology has an insignificant effect on pricing practice. Interestingly, pricing practice mediates the relationship between innovation strategy and system integration regarding firm performance. The findings of this study suggest that, in the formulation of such a strategy, service firms should consider the pricing factor. Telecommunications service providers could use this model to implement pricing practices particularly driven by innovation practices to achieve the desired performance. The study
\end{abstract}

(C) Asian Academy of Management and Penerbit Universiti Sains Malaysia, 2017. This work is licensed under the terms of the Creative Commons Attribution (CC BY) (http://creativecommons. org/licenses/by/4.0/). 
could also assist managers in understanding suitable pricing practices in the context of the telecommunications industry. The originality of this study lies in the effort to adjoin service innovation management practices with pricing practices that lead to improving the performance of the telecommunications industry.

Keywords: service innovation management, pricing practice, performance, telecommunications industry, Malaysia

\section{INTRODUCTION}

Service innovation has recently generated increasing consideration from academicians, service researchers, policy makers, governments and practitioners times at the global level (Ettlie \& Rosenthal, 2012; Rahman, Taghizadeh, Ramayah, \& Ahmad, 2015; Van Riel et al., 2013; Wang, Voss, Zhao, \& Wang, 2015). This growing attention has been due to changes in the conventional mindset of innovation. In fact, changes are occurring everywhere, increasing complexity within the environment (Van Riel, 2005). For example, variations in economic conditions lead to the opening of new markets while closing others (Van Riel, 2005). Moreover, customer expectations are also shifting in the market, placing companies in a difficult situation in attaining customer satisfaction (Oliver, Rust, \& Varki, 1997). This escalation subsequently increases the level of global competition and rivalry among companies (Van Riel, 2005). To overcome these challenges, service companies are required to develop innovative services.

However, successful service innovation depends not only on how a firm manages projects, coordinates inputs of different functions, and connects with its customers but also on being able to develop strategic approaches and a broad outlook (Tidd, Bessant, \& Pavitt, 2005). Scholars have admitted that managing innovation is not a simple task; rather, it is a complex process (Panesar \& Markeset, 2008). Most innovation projects face many challenges and demands despite the abilities of companies to design and produce high-quality products and services. Approximately $50 \%$ to $90 \%$ of innovation projects fail in the marketplace before achieving organisations' goals (Downey, 2007). This trend is particularly true in the service industry (Edvardsson \& Olsson, 1996). To overcome this complexity, management must have a balanced, comprehensive, and proactive approach (Ottenbacher, 2007). The literature on new service development has revealed that the growth and performance of any organisation rely on the efficient management of innovation in a competitive climate (Jiménez-Jiménez \& Sanz-Valle, 2011; Tidd \& Bessant, 2009). In the ever dynamic and competitive environment of the 21 st century, firms are struggling to improve performance and to remain ahead of 
their competitors. The need to thrive and to secure competitive advantages in an agile environment has led researchers to study the managerial practices of service innovation (Van Riel, 2005). However, questions can arise regarding the type of innovation practices that enable service companies to gain a competitive advantage and to improve their performance.

In the service innovation management literature, scholars have asserted that an organisation should consider five innovation management practices: innovation strategy, innovation process, cross-functional organisation, tools/technology, and system integration for new service developments (Tidd, Bessant, \& Pavitt, 2001). These management practices have significant influences on firm performance in the service sector (Hull, 2003; Hull \& Tidd, 2003a; Taghizadeh, Jayaraman, Ismail, \& Rahman, 2014a, 2014b).

Moreover, the new service development literature has perceived pricing to be one of the most important decisions that firms make when the initiation of new services is undertaken (Hultink, Griffin, Hart, \& Robben, 1997). Although pricing is one of the most complex decisions faced by companies (Indounas, 2006), it leaves pricing issues unaddressed and can result in barriers to the implementation of innovation (Milling \& Maier, 1994). Therefore, the complexity of a price decision requires adequate resources and coordination efforts (Dutta, Zbaracki, \& Bergen, 2003) to render service innovation successful (Maier, 1998).

In this regard, it is of interest to explore how well innovation management practices in alignment with pricing practices are implemented in developing countries to enhance the level of performance. As observed in the recent literature, scholars have modified and tested management theories and frameworks in emerging economies, which are typically built in the northern part of the globe (Barrett, Davidson, Prabhu, \& Vargo, 2015). Therefore, this study tests the role of pricing practices as an intervening variable in the relationship between innovation management practices and firm performance. To test this relationship, we focused on the telecommunications industry in the Malaysian context as a rapidly growing economy in Asia. There is a rapid revolution occurring in the telecommunications industry, in which customers anticipate frequent changes in service innovation features. Understandably, Malaysia is a hub for electrical and electronic goods; it is unsurprising that the telecommunications industry grows daily by making advancements and adding sophistication to its services to achieve targeted performance. However, to portray the chosen context, this paper is organised in an order that includes conceptualisation of the framework, hypothesis development, research methodology, and discussion. Finally, the study concludes with implications for future research. 


\section{CONCEPTUALISATION OF MODEL VARIABLES}

\section{Innovation Management Practices in Services}

Service innovation is essential to growth and to sustaining a competitive advantage among shareholders (Taghizadeh et al., 2014a). The service industry can gain a high level of performance enhancement by applying innovation (Jiménez-Jiménez \& Sanz-Valle, 2011; Ottenbacher, 2007; Sin, Tse, Heung, \& Yim, 2005), which results in gaining a competitive advantage (Taghizadeh \& Rahman, 2013). However, in the context of services, innovation is progressing slowly (Toivonen \& Tuominen, 2009). Until the 1980s, services were not examined or considered innovative during an initial stage of indifference (Camisón \& Monfort-Mir, 2011). Later, scholars focused on interactions among service providers and service users (Gallouj \& Windrum, 2009). To better explain the nature of services, researchers emphasised that there is a trend in which companies produce goods and services with mutual exclusiveness (Gallouj \& Savona, 2011).

However, in today's dynamic business environment, the service industry might not create sufficient innovations without innovative environment practices to achieve competitive advantages. In fact, scholars have argue that management practices to create an innovative environment play an important role in successful service innovation (Rahman et al., 2015).

An innovative environment focuses on the resources and climate needed to support service innovation. An innovative environment constitutes a number of different elements related to the management of innovation (Tidd \& Bessant, 2009). The service innovation literature has introduced different key areas to practice to support the development of an innovative environment, resulting in successful service development rates. These areas are innovation strategy, innovation process, cross-functional organisation, tools/technology, and system integration proposed by Tidd et al. (2001).

Innovation strategy focuses on having a clear innovation strategy that can be communicated and deployed effectively in the organisation. Innovation processes are about having effective enabling mechanisms for the innovation process from searching, selecting, implementing, and capturing new ideas. Cross-functional organisation provides coordination of people and a supportive climate for innovation. Tools/technology provides transformation/transaction capabilities and represents the usage of computer and information technology (CIT). Moreover, system integration provides and manages rich linkages to enable open innovation. Because multiple functions in service development cycles are simultaneously 
integrated into these practices, it is anticipated that such a blend of innovative practices would bring organisation to a competitive position. According to the literature, the practices start from the earliest stages of service development tasks, using structured processes and facilitating tools for launching new services (Hull, 2003). By integrating all of the functions simultaneously, an organisation can reduce the time required for developing and launching new services to enhance service quality and ensure a firm's competitiveness (Collins \& Hull, 2002).

\section{Pricing Practice}

Pricing practice refers to managerial decisions with regard to setting a marketdriven price for the services they offer. There are three critical perspectives in pricing practices, namely, consumer value-informed pricing, competition-informed pricing, and cost-informed pricing practices (Ingenbleek, Debruyne, Frambach, \& Verhallen, 2003). Value-informed pricing focuses on consumer willingness to pay for the perceived benefits of a market offering (Liozu, Hinterhuber, Boland, $\&$ Perelli, 2012). It can be measured by a consumer's perceived value of the service (Ingenbleek et al., 2003), which is calculated as the difference between the price that customers are willing to pay minus the benefits that they receive from the innovated service. More than $40 \%$ of managers are unable to correctly define consumer value pricing; therefore, price setting becomes a complex task for managers (Liozu et al., 2012). A competition-informed pricing approach refers to pricing decisions that are considered a benchmark in price setting. Competitioninformed pricing has the tendency to enhance the likelihood of setting the right price using a competitor's service innovation practices, including pricing that can match or exceed a firm's price for innovated services. The prices of competitive services and the competitive advantages of competitors dictate that a firm must evaluate the firm's position in the market vis-a-vis the competitors (Ingenbleek et al., 2003). Cost-informed pricing denotes the costs incurred in developing innovative services, the production processes involved, and the marketing efforts for new services. Information on a company's variable and fixed costs can help in determining a bottom-line price for innovative services to remain profitable and competitive in the market (Ingenbleek et al., 2003).

In this research, pricing practices are modelled as a second order formative construct, where first order constructs consist of reflective measurements that refer to the reflective-formative type. Based on this theory, it was confirmed that value-informed pricing, competition-informed pricing, and cost-informed pricing form the pricing practice factor. A formative approach represents an aggregation of individual beliefs into a single summary representation (Chin \& Gopal, 1995). Because these dimensions of pricing practice do not share a common theme of 
their second order and, as such, omit all of the dimensions, the conceptual domain of second order constructs (pricing practice) can change. Ingenbleek et al. (2003) noted that, to ensure the total depiction of pricing practices, customer value-, competition-, and cost-informed pricing must be together. Following Becker, Klein, and Wetzels (2012), the indicator approach was used in this research to model hierarchical latent variables. In the first stage of the repeated indicator approach, the latent variable scores are obtained for the first order constructs, which in the second stage serve as manifest variables in the hierarchical order construct (Figure 1).

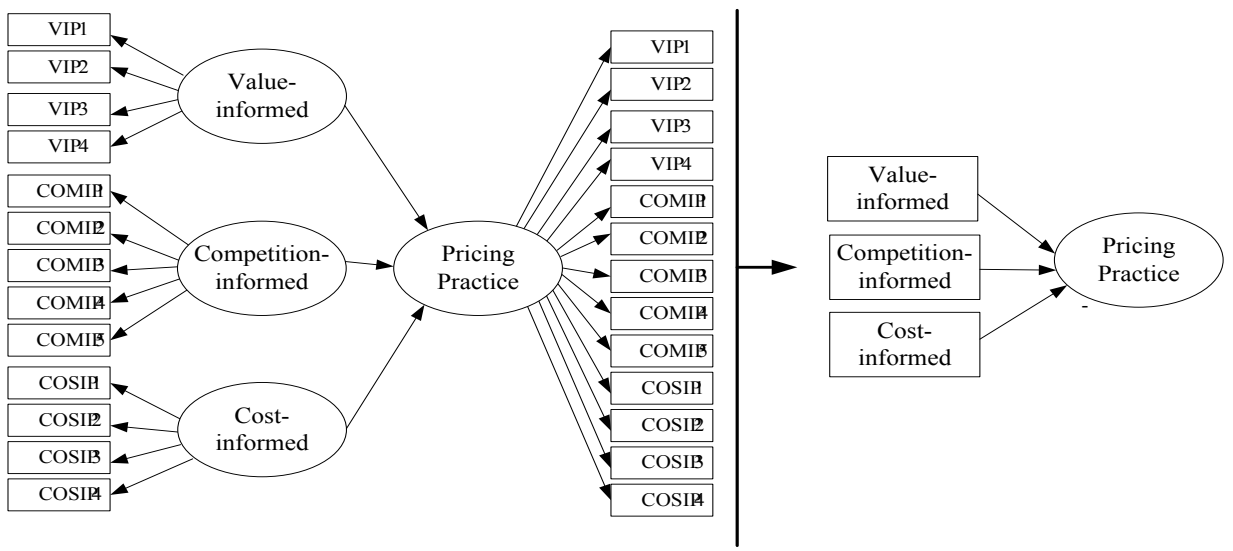

Figure 1. Pricing practice as second order construct

\section{Performance}

Resource-based view (RBV) theory suggests that the performance of firms depends on the relationships among available resources and capabilities to perceive and respond to market opportunities or threats. Innovation researchers have used the RBV to investigate how innovation oriented practices can lead to gaining a competitive advantage and can help firms to enhance their performance (Barney, 1991; Cetindamar \& Ulusoy, 2008; Davila, Epstein, \& Matusik, 2004). Implementing innovations has been acknowledged as the primary capability of a firm in adjusting to market conditions and change (Henri, 2006). Moreover, pricing is an ability, and setting the right price is essential for firms to capture competitive advantages and superior performance (Dutta et al., 2003; Teece, Pisano, \& Shuen, 1997). This ability requires coordination and the deployment of resources (Dutta et al., 2003). The literature has noted that pricing is a process associated with new product development, in which resources are organised in determining prices (Day \& Nedungadi, 1994). 
Performance demonstrates the business initiatives and strategies undertaken by a firm. In terms of market performance, the telecommunications industry is characterised by high knowledge intensive services through its relations with customers and cooperation with internal organisations (Segarra-Blasco, 2010). Therefore, it is important to study the influence of innovation activities on telecommunications market performance. Market performance includes attracting new customers, opening new markets, attaining market share (Ottenbacher, 2007), customer retention, and customer satisfaction (Sin et al., 2005). In terms of operational performance, because innovation addresses new services, product development and delivery time, it is important to evaluate the operational performance of the telecommunications industry. Operational performance includes service development and delivery process improvement (Hull \& Tidd, 2003a). Based on the detailed literature cited above, the research framework was conceptualised for the current study, and it is depicted in Figure 2.

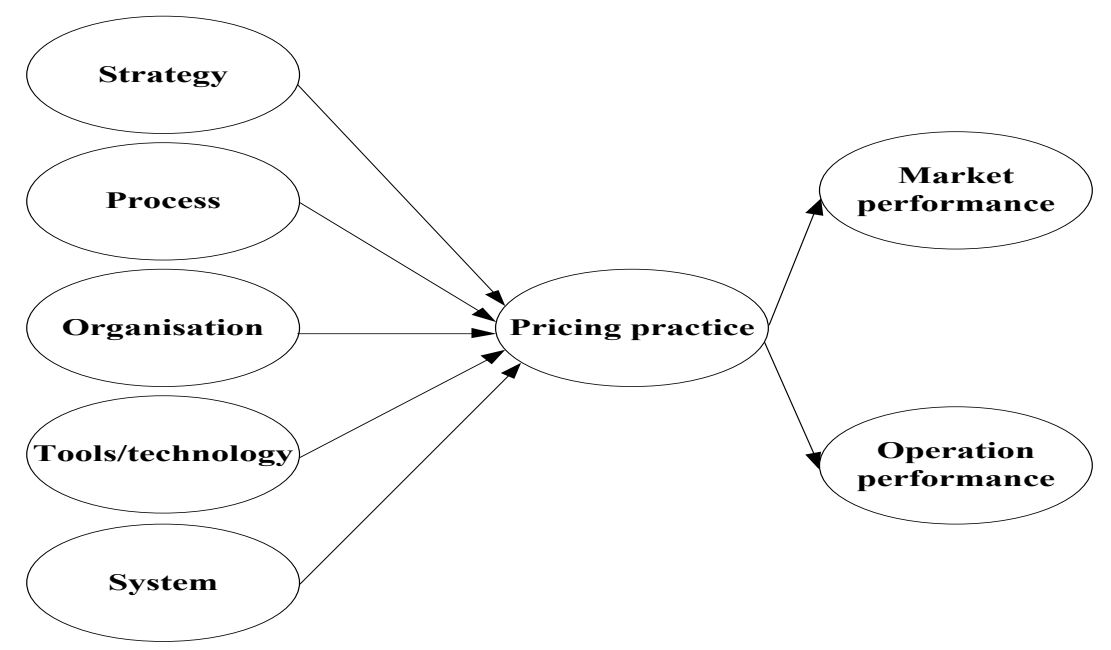

Figure 2. Conceptual research framework

\section{Hypothesis Development}

\section{The influence of service innovation management practices on pricing practices}

Innovation strategy, as the first component of service innovation management practices, is defined as a time-cost-based strategic positioning and resource allocation decision, which is planned in meeting firm objectives (Davila et al., 2004). It involves the decisions by which market or technology best matches organisational goals to deliver value and to build a competitive advantage 
(Taghizadeh, Jayaraman, Ismail, \& Rahman, 2016; Tidd \& Bessant, 2009). According to the scholarship, in the domain of innovation management, variation in price depends on a firm's overall strategy (Owen \& Trzepacz, 2002), and decisions about setting the right price require a company to formulate an innovation strategy (Vandermerwe, 2003). The standard practice of innovation strategy is to continue improving existing services through the utilisation of updated information about dynamic customers' needs, in addition to developing market-driven novel services (Ingenbleek, Frambach, \& Verhallen, 2010). Therefore, researchers have argued that firms must collect required information about the level and type of price that customers would prefer before a pricing decision can be made with the adoption of a multifunctional process in pricing practices (Ingenbleek et al., 2003). Because innovation strategy involves forecasting tools and techniques to predict future threats and opportunities (Tidd \& Bessant, 2009), it can assist managers in understanding customers' perceived value and in estimating competitors' current pricing strategies. Based on these considerations, the current study assumes that a firm's innovation strategy is likely to be instrumental in the implementation of the right pricing practice. Therefore, the following hypothesis would certainly be worth testing:

H1.1: Innovation strategy has a positive influence on pricing practices.

The second component of service innovation management practices, innovation process involves an organised and formal approach, by which all new service development phases are to be efficiently managed and controlled (Hull \& Tidd, 2003a). It also includes an external investigation and internal controls to develop new services (Hull, 2003), which can help firms in price decisions because, through an external investigation of processes, functional departments are involved in the procedures towards understanding the importance of addressing customer values, in line with the strategic movement of rivals in the market (Hull \& Tidd, 2003a). Therefore, it can facilitate firms in obtaining price-related information from customers and competitors. In addition, an internal assessment of processes involves an evaluation of standard practices towards the reduction of non-value activities, which can affect a company's costs in the development of new services (Hull, 2003). Therefore, internal process activists are likely to facilitate the evaluation of the variable costs of services. Considering the above discussion, the current study assumes that the practice of innovation processes can help firms in pricing practices. Therefore, the following hypothesis is formulated:

H1.2: Process has a positive influence on pricing practices. 
Cross-functional organisation is considered the third component of service innovation management practices, and the current study proposes that crossfunctional organisation can have an influence on pricing practices. One of the active features of cross-functional organisations is reflected in the effective coordination and mobilisation of human resources (Huang, Lai, Kao, \& Sung, 2014; Tidd \& Bessant, 2009). Employees representing different functional areas within an organisation contribute to the integrated focus on a defined objective towards improving innovation practices across all relevant divisions (Kotelnikov, 2001). Therefore, inter-functional coordination and cooperation are deemed instrumental in efficient innovation management and in the gathering of data about the right price from the perspectives of the firm, customers, and competitors. It can be assumed that customers' perceptions of service value, break-even prices, and the degree of competition can be understood through the propensities of crossfunctional organisations. Therefore, the following hypothesis would be worthwhile for testing:

H1.3: Cross-functional organisation has a positive influence on pricing practices.

Tools/technology is the fourth component of service innovation management practices. Today's organisations require a collaborative and creative workplace, which can be facilitated through CIT tools (Klein \& Dologite, 2000). According to Collins and Hull (2002), organisational transformation and transaction capabilities are enhanced by the adoption of CIT tools, such as communication devices and data distribution approaches. Furthermore, the researcher believes that, as an enabler, CIT tools help firms in continuously updating the service development process (Hull \& Tidd, 2003b). It also allows management to evaluate and control an entire project through stored day-to-day information regarding staff training in reviewing consumer and user satisfaction, evaluating projects, and auditing (Mudrak, van Wagenberg, \& Wubben, 2005). CIT provides the capability of reviewing all of a firm's projects to improve overall business performance (Tidd et al., 2005). The transformation and transaction capabilities of firms, along with continuous updating of the service development process, can facilitate firms in gathering price-related information more rapidly. Therefore, the following hypothesis was proposed for testing:

H1.4: Tools/technology has a positive influence on pricing practices.

The current study assumes that system integration (fifth component of service innovation management practices) can have an effect on pricing practices. According to the scholarship, system integration helps firms to have close relationships 
with stakeholders (Panesar \& Markeset, 2008) to generate a sound knowledge base (Liker, Collins, \& Hull, 1999). A knowledge gatherer from a community of stakeholders can facilitate firms in obtaining information from customers and competitors regarding new services and offering prices. Since pricing practice is a multifunctional process (Ingenbleek et al., 2003), it not only requires external information about customers, but it also involves internal information about a company's costs. Therefore, integration of people, internally and externally, into innovative systems can have strong effects on the pricing practice process. In addition, establishing a balanced portfolio of competitive advantages for which customers are willing to pay and establishing open communication channels for all functions (Hull \& Tidd, 2003a) can help firms in the determination of overall pricing practices. Therefore, based on the above discussion, the following hypothesis would be relevant for testing:

H1.5: System integration has a positive influence on pricing practices.

\section{Pricing practices and performance}

The current study hypothesises that pricing practices can affect performance in terms of market performance and operational performance. According to the previous study, implementing appropriate pricing practice maximises the probability of better performance (Hultink et al., 1997). Similarly, Dutta et al. (2003) argued that a company's capabilities in setting the correct price drives the superior performance of firms. Previous studies have supported the notion that, in a competitive environment, organisations cannot ignore pricing practices in light of these practices creating value, not only for the company but also for customers (Nagle, Hogan, \& Zale, 2010). Value-informed pricing, competition-informed pricing, and cost-informed strategies were found to strongly contribute to product performance (Ingenbleek et al., 2003; Ingenbleek et al., 2010). Therefore, pricing practices through value-, competition-, and cost-informed pricing are predicted to positively affect performance. Thus, the following hypotheses are presented for testing:

H2.1: Pricing practices have a positive influence on market performance.

H2.2: Pricing practices have a positive influence on operational performance.

\section{The mediating role of pricing practices}

A direct relationship between the components of innovation management practices and operational performance has been examined in prior studies (Hull \& Tidd, 
2003a, 2003b; Taghizadeh et al., 2014a). Additionally, researchers have examined value-informed pricing as an element of pricing practice and as a mediator in the relationship between market orientation and performance (Ingenbleek et al., 2010). However, there is barely any research being conducted to examine the impact of the components of innovation management practices on the performance of service firms or to consider the possible role of pricing practices in such relationships. Towards addressing this gap in the literature, this study introduced pricing practices as a mediator. The rationale for testing this mediating effect arises from service customers' increasing interests in the pricing of services. Collins and Hull (2002) noted that customer expectations play an important role in the effective management of innovation and firm performance. Clayton (2003) noted that innovative firms employ their innovation policies in line with parity pricing principles, emphasising long-term growth rather than immediate profit maximisation. Therefore, this study assumes that pricing practices could play the role of mediator ion the relationship between the components of innovation management practices and performance in terms of markets and operations. Regarding testing of the above propositions related to the mediating role of pricing practices of innovative service firms, the following hypotheses are presented:

H3.1-H3.10: Pricing practices mediate the relationship between the components of innovation management practices and both market and operational performance.

\section{RESEARCH METHODOLOGY AND DATA ANALYSIS}

To test the research framework and hypotheses, we chose telecommunications companies from Malaysia. The rationale for choosing a single industry was based on the notion that it provides an accurate picture of a specific context, as suggested by Slater (1995). The unit of analysis was all of the branch offices and outlets of the telecommunications companies. The respondents for the current study were primarily managers from marketing and operations. Purposive sampling was confined to a specific type of person who can provide the desired information, whether they are the only ones who have it or whether they conform to some criterion set by the researchers (Sekaran \& Bougie, 2010). The inclusion criteria for a respondent of the present research would be a manager who addresses the marketing and innovation activities of the companies. The total number of questionnaires received was 258 , and the total usable questionnaires for the analysis totalled 249 . 
A five-point scale, where 1 represented strongly disagree to 5 represented strongly agree, was used to measure the responses. All of the constructs and items were adapted from the extant literature and were modified to suit the purposes of this study. Items related to innovation management practices were adapted from Hull (2004), Hull and Tidd (2003a), and Tidd and Bessant (2009), items related to pricing practices were adapted from Ingenbleek et al. (2003), items related to market performance were adapted from Ottenbacher (2007) and Sin et al. (2005), and items related to operational performance were adapted from Hull and Tidd (2003a). VB-SEM using partial least squares (PLS) was employed as a statistical technique to analyse the collected data.

The majority of the respondents' ages were between 31 and 40 years old (48.2\%), followed by $21-30$ years old $(30.5 \%), 41-50$ years old $(17.3 \%)$, and 51 or older (4\%). A total of $145(58.2 \%)$ respondents were male, and $104(41.8 \%)$ respondents were female. In terms of education level, $148(59.4 \%)$ respondents held a bachelor's/honours degree, $43(17.3 \%)$ had a postgraduate/master degree, $4(1.6 \%)$ had a doctoral degree, and $54(21.7 \%)$ had other levels of education. The majority of the respondents' work experience in the telecommunications sector totalled 5 years or less $(41 \%)$, followed by $6-8$ years $(28.1 \%), 12$ years or more $(15.7 \%)$, and $9-11$ years $(15.3 \%)$. The working experience of the respondents in their current companies was 5 years or less $(55 \%), 6-8$ years $(22.9 \%), 9-11$ years $(6.4 \%)$, and 12 years or more $(15.7 \%)$.

\section{Results of Measurement Models}

To ensure that there was no common method bias in the questionnaire survey, we performed Harman's single factor test, which revealed that the first factor accounted for $34.613 \%$ of the variance, which is less than the threshold level of $50 \%$ of total variance explained (Podsakoff, MacKenzie, Lee, \& Podsakoff, 2003).

We considered the structural equation model (SEM) with SmartPLS software, version 3, to achieve our research objectives and to analyse the measurement and structural model. The research followed the guidelines proposed by Becker et al. (2012) in presenting the results. As shown in Table 1, at the beginning, convergent validity was examined. Convergent validity includes indicator loadings, average variance extracted (AVE), and composite reliability (CR). The results showed that the indicator loading for all of the items exceeded the recommended value of 0.7 (Hair, Hult, Ringle, \& Sarstedt, 2014). However, STR1 and OP5 decreased due to having loading less than 0.7 . AVE was in the range of 0.569 and 0.735 , which exceeded the recommended value of greater than 0.50 , and the CR ranged from 
0.882 to 0.922 , which exceeded the recommended value of 0.7 (Hair, Black, Babin, \& Anderson, 2009).

For the second order construct analysis, the parameter estimates of indicator weights, significance of weights, and multicollinearity of indicators were inspected. The recommended indicator weight is $>0.1$ (Lohmöller, 1989) or 0.2 (Chin, 1998). The weights of items exceeded the recommended value of 0.2 (Chin, 1998). A significance level of at least 0.05 suggests that an indicator is relevant to the construction of the formative index and therefore demonstrates a sufficient level of validity. The result showed a significance level at 0.01 . The degree of multicollinearity among the formative indicators was assessed by VIF, which was less than 3.33 (Diamantopoulos \& Siguaw, 2006). The degree of multicollinearity among the other variables was also assessed, and the results indicated a VIF less than 3.33. Table 1 shows the results of the measurement model.

Table 1

Results of measurement model

\begin{tabular}{|c|c|c|c|c|c|c|c|}
\hline $\begin{array}{l}\text { First order } \\
\text { constructs }\end{array}$ & $\begin{array}{l}\text { Second order } \\
\text { constructs }\end{array}$ & Scale & Item & Loading & $\mathrm{CR}$ & AVE & VIF \\
\hline \multirow[t]{4}{*}{ Strategy } & & Reflective & STR2 & 0.747 & 0.882 & 0.652 & 1.881 \\
\hline & & & STR3 & 0.831 & & & \\
\hline & & & STR4 & 0.863 & & & \\
\hline & & & STR5 & 0.783 & & & \\
\hline \multirow[t]{5}{*}{ Process } & & Reflective & PRCl & 0.768 & 0.892 & 0.622 & 2.166 \\
\hline & & & PRC2 & 0.769 & & & \\
\hline & & & PRC3 & 0.824 & & & \\
\hline & & & PRC4 & 0.797 & & & \\
\hline & & & PRC5 & 0.784 & & & \\
\hline \multirow[t]{5}{*}{ Organisation } & & Reflective & ORG1 & 0.806 & 0.919 & 0.694 & 2.272 \\
\hline & & & ORG2 & 0.855 & & & \\
\hline & & & ORG3 & 0.845 & & & \\
\hline & & & ORG4 & 0.889 & & & \\
\hline & & & ORG5 & 0.766 & & & \\
\hline \multirow{5}{*}{$\begin{array}{l}\text { Tools/ } \\
\text { technology }\end{array}$} & & Reflective & TOL1 & 0.813 & 0.896 & 0.633 & 2.211 \\
\hline & & & TOL2 & 0.837 & & & \\
\hline & & & TOL3 & 0.845 & & & \\
\hline & & & TOL4 & 0.776 & & & \\
\hline & & & TOL5 & 0.700 & & & \\
\hline
\end{tabular}


Seyedeh Khadijeh Taghizadeh et al.

Table 1 (continued)

\begin{tabular}{|c|c|c|c|c|c|c|c|}
\hline $\begin{array}{l}\text { First order } \\
\text { constructs }\end{array}$ & $\begin{array}{l}\text { Second order } \\
\text { constructs }\end{array}$ & Scale & Item & Loading & $\mathrm{CR}$ & AVE & VIF \\
\hline \multirow[t]{6}{*}{ System } & & Reflective & SYS1 & 0.815 & 0.929 & 0.685 & 2.483 \\
\hline & & & SYS2 & 0.878 & & & \\
\hline & & & SYS3 & 0.850 & & & \\
\hline & & & SYS4 & 0.822 & & & \\
\hline & & & SYS5 & 0.816 & & & \\
\hline & & & SYS6 & 0.784 & & & \\
\hline \multirow{4}{*}{$\begin{array}{l}\text { Value- } \\
\text { informed } \\
\text { pricing }\end{array}$} & & Reflective & VIP1 & 0.829 & 0.909 & 0.716 & 1.884 \\
\hline & & & VIP2 & 0.911 & & & \\
\hline & & & VIP3 & 0.869 & & & \\
\hline & & & VIP4 & 0.769 & & & \\
\hline \multirow{5}{*}{$\begin{array}{l}\text { Competition- } \\
\text { informed } \\
\text { pricing }\end{array}$} & & Reflective & COM1 & 0.799 & 0.917 & 0.689 & 2.274 \\
\hline & & & $\mathrm{COM} 2$ & 0.844 & & & \\
\hline & & & COM3 & 0.866 & & & \\
\hline & & & COM4 & 0.867 & & & \\
\hline & & & COM5 & 0.769 & & & \\
\hline \multirow{9}{*}{$\begin{array}{l}\text { Cost- } \\
\text { informed } \\
\text { pricing }\end{array}$} & & Reflective & CST1 & 0.850 & 0.917 & 0.735 & 2.028 \\
\hline & & & $\mathrm{CST} 2$ & 0.893 & & & \\
\hline & & & CST3 & 0.866 & & & \\
\hline & & & CST4 & 0.818 & & & \\
\hline & & & & Weights & & $\mathrm{t}$-value & VIF \\
\hline & Pricing practice & Formative & $\begin{array}{l}\text { Value- } \\
\text { informed }\end{array}$ & 0.433 & - & $4.376^{* * *}$ & 1.787 \\
\hline & & & $\begin{array}{l}\text { Competition- } \\
\text { informed }\end{array}$ & 0.224 & - & $2.081^{* *}$ & 2.204 \\
\hline & & & $\begin{array}{l}\text { Cost- } \\
\text { informed }\end{array}$ & 0.510 & - & $6.296^{* *}$ & 1.747 \\
\hline & & & & Loading & $\mathrm{CR}$ & AVE & \\
\hline \multirow{5}{*}{$\begin{array}{l}\text { Market } \\
\text { performance }\end{array}$} & & Reflective & MP1 & 0.755 & 0.904 & 0.653 & \\
\hline & & & MP2 & 0.839 & & & \\
\hline & & & MP3 & 0.869 & & & \\
\hline & & & MP4 & 0.832 & & & \\
\hline & & & MP5 & 0.737 & & & \\
\hline \multirow{9}{*}{$\begin{array}{l}\text { Operational } \\
\text { performance }\end{array}$} & & Reflective & OP1 & 0.830 & 0.922 & 0.569 & \\
\hline & & & $\mathrm{OP} 2$ & 0.787 & & & \\
\hline & & & OP3 & 0.746 & & & \\
\hline & & & OP4 & 0.711 & & & \\
\hline & & & OP6 & 0.700 & & & \\
\hline & & & OP7 & 0.721 & & & \\
\hline & & & OP8 & 0.728 & & & \\
\hline & & & OP9 & 0.745 & & & \\
\hline & & & OP10 & 0.811 & & & \\
\hline
\end{tabular}

Note $\mathrm{CR}=$ composite reliability; $\mathrm{AVE}=$ average variance extracted; $\mathrm{VIF}=$ variance inflation factor; $* * p<0.01$ 
After convergent validity, discriminant validity was tested (the degree to which items differentiate among constructs or measure distinct concepts). Discriminant validity was assessed using the heterotrait-monotrait ratio of correlations (HTMT), based on the multitrait-multimethod matrix suggested by Henseler, Ringle, and Sarstedt (2015).

With HTMT, there are two criteria. If the HTMT value is greater than an $\mathrm{HTMT}_{85}$ value of 0.85 (Kline, 2015) or an $\mathrm{HTMT}_{90}$ value of 0.90 (Gold \& Arvind Malhotra, $2001)$, then the discriminant validity is questionable. The second criterion is to test the null hypothesis $(\mathrm{H} 0: \mathrm{HTMT} \geq 1)$ against the alternative hypothesis (H1: HTMT $<1$ ), and if the confidence interval contains 1 (i.e., H0 holds), indicating a lack of discriminant validity (Henseler et al., 2015). As shown in Table 2, all of the values

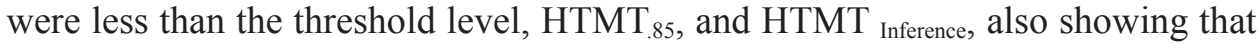
the confidence interval did not show a value of 1 in any of the constructs, thus indicating that discriminant validity has been ascertained.

\section{Results of Structural Model}

The results of the structural model are presented in Table 3. The prime evaluation criteria for the goodness of the structural model are $\mathrm{R}^{2}$, which measures the coefficient of determination, standard beta, and t-values via a bootstrapping procedure, with a resample of 5000; $\mathrm{f}^{2}$ measures effect size and the predictive relevance $\left(\mathrm{Q}^{2}\right)$, as suggested by Hair et al. (2014).

The results of the current research show that the $\mathrm{R}^{2}$ value for pricing practices is 0.417 , market performance is 0.129 , and operational performance is 0.293 . However, the maximum $\mathrm{R}^{2}$ values are for pricing practices, suggesting that $41.7 \%$ of the variance in pricing practices can be explained by components of the innovation management practices (Table 3).

Hair et al. (2014) suggested examining the changes in the $\mathrm{R}^{2}$ value to determine the $\mathrm{f}^{2}$. The method suggested is to omit a specific exogenous construct from the model and to determine whether $\mathrm{R}^{2}$ changes. It can be used to evaluate whether the omitted construct has a substantive impact on the endogenous constructs. Table 3 shows the results of $\mathrm{f}^{2}$. Following Cohen's (1988) guideline, the effect sizes of $0.02,0.15$, and 0.35 , respectively, represent small, medium, and large effects. The results show that the effect size of strategy and system on pricing practices is small. The effect size of pricing practices on market performance is medium, and on operational performance, it is large. 
Finally, we assessed the predictive relevance of the model through the blindfolding procedure, which is a predictive sample reuse technique, popularly known as the Stone-Geisser's $\mathrm{Q}^{2}$, that can be applied as a criterion for predictive relevance, in addition to examining the magnitude of the $\mathrm{R}^{2}$. Henseler, Ringle, and Sinkovics (2009) recommended utilising this measure to assess a research model's capability to predict. Based on the blindfolding procedure, the results indicated that the $\mathrm{Q}^{2}$ values for pricing practice $\left(\mathrm{Q}^{2}=0.285\right)$, market performance $\left(\mathrm{Q}^{2}=0.0 .078\right)$, and operational performance $\left(\mathrm{Q}^{2}=0.154\right)$ were greater than 0 , suggesting that the model has sufficient predictive relevance. Hair et al. (2014) stated that values of $0.02,0.15$, and 0.35 indicate that an exogenous construct has a small, medium, or large predictive relevance for a certain endogenous construct.

The results of the path coefficient revealed that innovation strategy has a positive relationship with pricing practice $(\beta=0.213, p<0.01)$, innovation process has a positive relationship with pricing practice $(\beta=0.133, p<0.05)$, cross-functional organisation has a positive relationship with pricing practice $(\beta=0.154, p<0.05)$, tools/technology has no relationship with pricing practice, and lastly, system integration has a positive relationship with pricing practice $(\beta=0.198, p<0.01)$. Thus, H1.1, H1.2, H1.3, and H1.5 were supported, but H1.4 was not supported.

The relationships of pricing practices with market performance $(\beta=0.461$, $p<0.01)$ and operational performance $(\beta=0.507, p<0.01)$ were found to be significant (Table 3 ). Therefore, both H2.1 and H2.2 were supported.

To test the requirements of mediation effects, the t-test via non-parametric procedure bootstrapping was performed. In the non-parametric PLS path modelling approach, a non-parametric bootstrapping procedure was administered to test the significance of the mediating effect, as suggested by Hair et al. (2014). According to Hayes (2009) and Preacher and Hayes (2008), mediation was considered to be occurring, while the indirect relationship between independent and dependent variables was ultimately significant. In this study, 4 indirect relationships out of 10 were proved to be significant. The mediating roles of pricing practices in the relationship between innovation strategy and market performance $(t$-value $=2.734$, $p<0.01)$, and operational performance $(t$-value $=2.998, p<0.01)$ were significant. The mediating roles of pricing practices in the relationships of innovation process, cross-functional, and tools/technology with organisation performance in terms of market and operational performance were insignificant. The mediating roles of pricing practice in the relationship of system integration with market performance $(t$-value $=2.678, p<0.01)$ and operational performance $(t$-value $=2.836$, $p<0.01$ ) were significant. Table 3 shows the results. Therefore, H3.1, H3.2, H3.9, and $\mathrm{H} 3.10$ were supported. 
Service Innovation Management and Pricing Practice

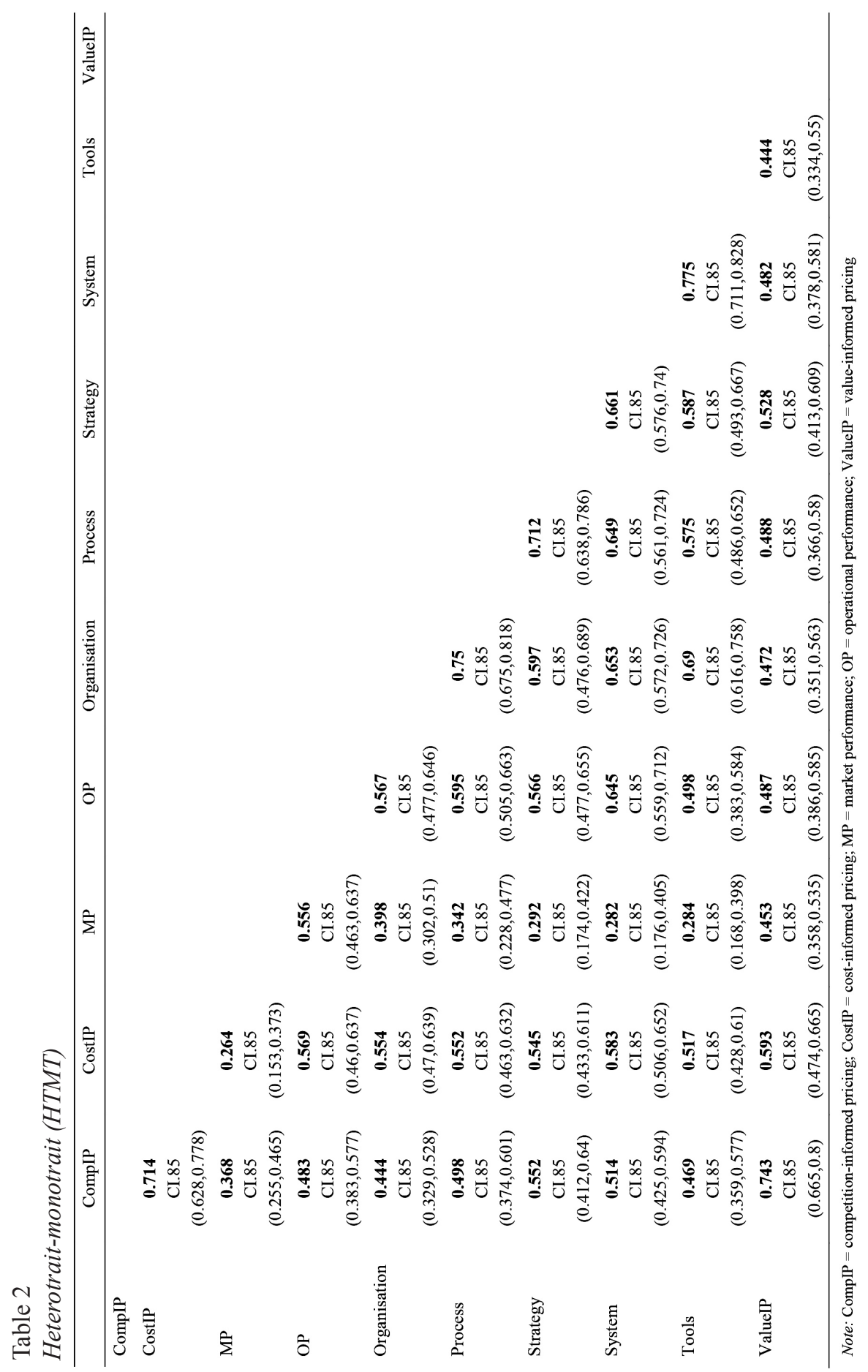


Seyedeh Khadijeh Taghizadeh et al.

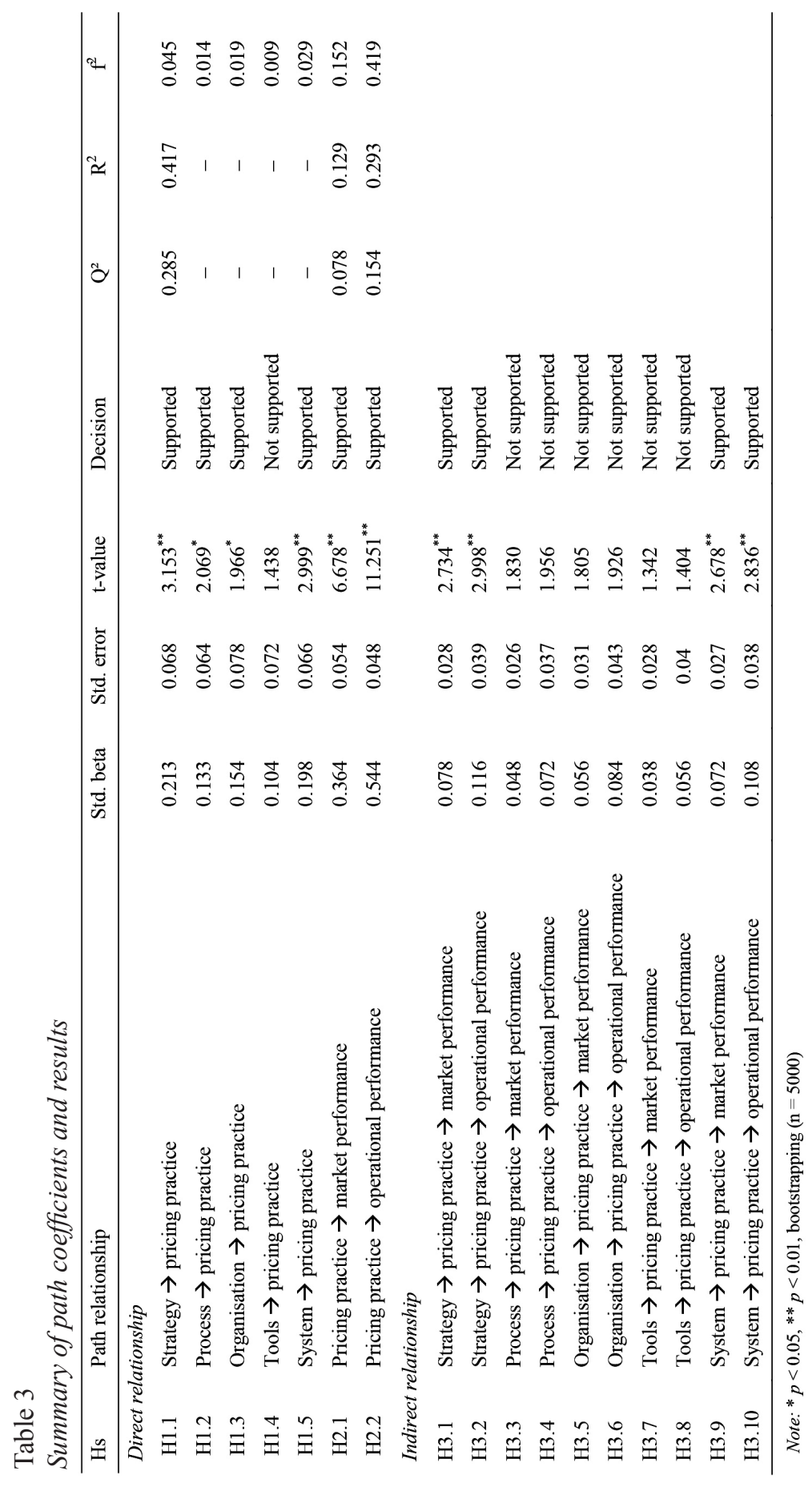




\section{DISCUSSION}

The objective of the study was to test the role of pricing practices as an intervening variable in the relationship between service innovation practices (innovation strategy, innovation process, cross-functional organisation, tools/technology, and system integration) and firm performance. The findings revealed that innovation strategy, innovation process, cross-functional organisation, and system integration have positive relationships with pricing practices, as predicted before the study. Strategies of conducting market research for developing new services, well managed and controlled innovation processes, and a win-win relationship with external parties facilitate managerial practices in gathering knowledge. The practice of gathering price information from customers enables telecommunications companies to understand customer sensitivity regarding price and how customers perceive the pricing of new services. Understanding customer perceptions helps companies to decrease the likelihood of pricing mistakes, such as overpricing or underpricing. Mapping processes increase the valuable activities of management in defining a customer's perceived value of a new service development. In addition, setting standards for the performance of services provides companies with an advantage over alternatives to particular services. It is believed that institutionalising continuous improvement processes enables telecommunications companies to gather information about the strategic movement of rivals and their degree of competition in the market. In fact, it increases the likelihood of setting the right price by knowing a competitor's innovation, with a service that matches or even exceeds the firm's services, which can affect performance. Furthermore, an internal assessment of processes involves measuring standard practices with the goal of reducing non-value activities, which can affect a company's costs for new service development. Similarly, social integration between internal functions and external organisation and linkage among stakeholders can help companies in price-related decisions. A decision for setting the correct price can be viewed as a paramount competitive advantage for the telecommunications industry. Specifically, in the context of Malaysia, it can be asserted that, due to market competitiveness, it is important to consider the innovation strategy and innovation system, which would have noteworthy impacts on the pricing practices of the offered services.

In other words, innovation strategy has the highest level of impact on pricing practices, followed by system integration. The telecommunications market in Malaysia is also complex to some extent. The country is a famous tourist destination; therefore, a large number of multinationals are present in the country. In addition, the country itself is home to three racial segments with rich and diverse cultures. Hence, to comply with such diverse customers, it is important to consider 
innovation strategy to ensure pricing practices. The cross-functional organisation and innovation process is the least important element in driving pricing practices. The findings of the current study demonstrate that pragmatism in the service innovation literature regarding organisational decisions about the best pricing practices for an innovative service would be facilitated by the correct managerial strategic orientation. Moreover, tools/technology surprisingly has an insignificant relationship with pricing practices. Malaysia is a well-developed country with trendy technological advancement. It was presumed that tools/technology would influence the performance of pricing practices, perhaps because of the nature of these practices, which emphasise internal activities and the collaboration of firms more. However, it is therefore can be assumed that technology or other technological devices are not influential factors in devise pricing practices in the telecommunications industry.

In addition, the pricing practice was found to significantly influence the market and operational performance, suggesting that pricing practices are critical for achieving better service growth, supply systems, new market creation, a better share of the market, and enhanced customer satisfaction and their long-term retention. The above results were supported by Dutta et al. (2003), who argued that a company's capabilities in setting the right price drives better performance of firms. They are the results of well-predicted hypotheses, which affirm significant relationships of market and operational performance with pricing practice. The results indicate that, if the pricing is set with proper structure and with accurate relevancy, the market and operational performance of the telecommunication industry will obviously increase. In fact, it is the assertion that, in any service industry, pricing practices would create an influential factor in attaining market and operational performance.

Placing pricing practices in a mediating position, the outcomes clearly delineate that innovation strategy and systems integration become instrumental in achieving both market and operational performance, with pricing practices playing a filtering role. Therefore, the results indicate that innovation strategy and systems integration can be influential in enhancing the level of organisational performance through pricing practices. Innovation strategy and system integration between internal functions and external organisation result in mutual fine-tuning among the stakeholders in the value chain to generate and deploy resources in alignment with customer needs to achieve better performance. Therefore, listening to customers and customising services evidently help in integrating practices to open a new market, capturing market share, satisfying customers and attaining their long-term retention, developing new services, and improving delivery processes. 


\section{IMPLICATIONS AND FUTURE RESEARCH}

The knowledge gained from this research adds yet another application to the resource-based theory with empirical evidence from the telecommunications sector. With this study, it can be claimed that the logical sequence of the RBV theory can also be explained in the context of the SPOTS (strategy, process, cross-functional organisation, tools/technology, and system integration) model, pricing practices, and performance. Following Dutta et al. (2003), who observed that pricing is a capability that requires resources and coordination, the present study shows that innovation strategy, processes, cross-functional organisation, and system integration are the central resources for pricing practices and that pricing requires coordination within the new service development process. These findings suggest that the resources of the telecommunications sector are strategy, processes, organisation, and systems. These resources then help to create the ability of pricing practice in this context. Finally, pricing practice as an ability will lead to better performance of the telecommunications companies in Malaysia. Further, the mediating role of pricing practice can add value in the innovation and pricingrelated literature. Hence, this study could bring the pricing and market-orientation literatures closer to each other, therefore enhancing insight into how marketoriented innovators can be superior performers.

The current study also contains a broad range of policy implications, particularly for the managers of the telecommunications industry. Conceptual refinement has been established in this study, indicating that pricing practices play facilitating roles in the overall context of service innovation management. Regardless of the innovation applied to o strategy, process, cross-functional organisation, and system integration, which are the factors influencing pricing, efforts must be exerted to spend minimal costs for service innovation; otherwise, the pricing of services might increase. Furthermore, in the name of service innovation, customers might not like to spend more unless the services are worth the price, ensuring quality of services. The telecommunications service providers could consider that these matters create value for the services offered to customers. Setting standards for the performance of services and mapping processes to reduce non-value-added activities might improve process enhancement for operational performance. Cross-functional teamwork could improve policy decisions for future industrial management.

The proposed framework is expected to be a contemporary guideline for companies and business managers. It is important for managers to understand the factors driving pricing practices in the context of service innovation management practices. In real scenarios, managers should consider the ability to change existing 
services rapidly to set pricing practices and improve innovation performance. The business manager might also improve a documentation process, which will enable adjusting to competitors' pricing strategies to result in the desired performance. Further, opening different communication channels along the value chain of the organisation will influence the setting of prices based on the market structure and the strength of competitors. Subsequently, it is expected that telecommunications companies might enjoy the benefits of the market and operational performances. Finally, the model could be applicable to other related industries, such as electronics and software. Managers from other industries might incorporate the notion of embracing pricing in their business strategy to be successful in service innovation management.

Future research could test the model in other service industries, such as hotels, banks, electronics, software, etc., to understand the level of importance of valueinformed pricing and competition-informed pricing in business strategies to be successful in service innovation management.

\section{CONCLUSION}

Taken together, the results that have been divulged through this study, mainly regarding pricing practices, truly mirror the competitive environment that exists in the Malaysian telecommunications industry. The study also demonstrates the significance of pricing practices, along with the importance of innovation strategy, innovation process, cross-functional organisation, and system integration to market and operational performance. It deploys this notion not only to offer a range of advantages to customers but also to define prices that complement the insights of benefits and other market players' actions. It asserts that business managers should consider the scope of the market and operational performance when setting the correct prices for new services. Based on the effective pricing mechanism that embodies the actions of customers, costs, and competitors, companies would truly benefit in terms of upgraded features and higher quality of delivery processes.

\section{REFERENCES}

Barney. (1991). Firm resources and sustained competitive advantage. Journal of Management, 17(1), 99-120. https://doi.org/10.1177/014920639101700108

Barrett, M., Davidson, E., Prabhu, J., \& Vargo, S.L. (2015). Service innovation in the digital age: Key contributions and future directions. MIS Quarterly, 39(1), 135154. https://doi.org/10.25300/MISQ/2015/39:1.03 
Becker, J.-M., Klein, K., \& Wetzels, M. (2012). Hierarchical latent variable models in PLS-SEM: Guidelines for using reflective-formative type models. Long Range Planning, 45(5), 359-394. https://doi.org/10.1016/j.lrp.2012.10.001

Camisón, C., \& Monfort-Mir, V.M. (2011). Measuring innovation in tourism from the Schumpeterian and the dynamic-capabilities perspectives. Tourism Management, 33(4), 776-789. https://doi.org/10.1016/j.tourman.2011.08.012

Cetindamar, D., \& Ulusoy, G. (2008). Innovation performance and partnerships in manufacturing firms in Turkey. Journal of Manufacturing Technology Management, 19(3), 332-345. https://doi.org/10.1108/17410380810853768

Chin, W.W. (1998). The partial least squares approach for structural equation modeling. In G.A. Marcoulides (Ed.), Modern methods for business research (pp. 295-336). New York: Psychology Press.

Chin, W.W., \& Gopal, A. (1995). Adoption intention in GSS: Relative importance of beliefs. ACM SigMIS Database, 26(2-3), 42-64. https://doi.org/10.1145/217278.217285

Clayton, T. (2003). Service innovation: Aiming to win. In J. Tidd \& F.M. Hull (Eds.), Service innovation: Organizational responses to technological opportunities and market imperatives (pp. 113-136). London: Imperial College Press. https://doi. org/10.1142/9781848161306_0005

Cohen, J. (1988). Statistical power analysis for the behavioral sciencies. Hillsdale, NJ: Erlbaum: Routledge. https://doi.org/10.1002/bs.3830330104

Collins, P.D., \& Hull, F.M. (2002). Early simultaneous influence of manufacturing across stages of the product development process: Impact on time and cost. International Journal of Innovation Management, 6(1), 1-24. https://doi.org/10.1142/ S1363919602000501

Davila, T., Epstein, M.J., \& Matusik, S.F. (2004). Innovation strategy and the use of performance measures. In M.A. Malina (Ed.), Advances in management accounting (vol. 13, pp. 27-58). Emerald Group Publishing Limited. https://doi. org/10.1016/S1474-7871(04)13002-5

Day, G.S., \& Nedungadi, P. (1994). Managerial representations of competitive advantage. The Journal of Marketing, 58(2), 31-44. https://doi.org/10.2307/1252267

Diamantopoulos, A., \& Siguaw, J.A. (2006). Formative versus reflective indicators in organizational measure development: A comparison and empirical illustration. British Journal of Management, 17(4), 263-282. https://doi.org/10.1111/j.14678551.2006.00500.x

Downey, J. (2007). Innovation management. Topic Gateway Series No. 38. London: The Chartered Institute of Management Accountants.

Dutta, S., Zbaracki, M.J., \& Bergen, M. (2003). Pricing process as a capability: A resourcebased perspective. Strategic Management Journal, 24(7), 615-630. https://doi. org $/ 10.1002 / \mathrm{smj} .323$

Edvardsson, B., \& Olsson, J. (1996). Key concepts for new service development. The Service Industry Journal, 16(2), 140-164. https://doi.org/10.1080/02642069600000019

Ettlie, J.E., \& Rosenthal, S.R. (2012). Service innovation in manufacturing. Journal of Service Management, 23(3), 440-454. https://doi.org/10.1108/09564231211248499 
Gallouj, F., \& Savona, M. (2011). Towards a theory of innovation in services: A state of the art. In F. Gallouj \& F. Djellal (Eds.), The handbook of innovation and services: A multi-disciplinary perspective. United Kingdom: Cheltenham.

Gallouj, F., \& Windrum, P. (2009). Services and services innovation. Journal of Evolutionary Economics, 19(2), 141-148. https://doi.org/10.1007/s00191-008-0123-7

Gold, A.H., \& Arvind Malhotra, A.H.S. (2001). Knowledge management: An organizational capabilities perspective. Journal of Management Information Systems, 18(1), 185-214. https://doi.org/10.1080/07421222.2001.11045669

Hair, J.F., Black, W.C., Babin, B.J., \& Anderson, R.E. (2009). Multivariate data analysis. Upper Saddle, New Jersey: Pearson Prentice Hall. https://doi.org/10.1016/j. csda.2008.11.030

Hair, J.F., Hult, G.T.M., Ringle, C.M., \& Sarstedt, M. (2013). A primer on partial least squares structural equation modeling (PLS-SEM). California: Sage Publications, Inc.

Hair, J.F., Hult, G.T.M., Ringle, C.M., \& Sarstedt, M. (2014). A primer on partial least squares structural equation modeling (PLS-SEM). Los Angeles: Sage Publications.

Hayes, A.F. (2009). Beyond Baron and Kenny: Statistical mediation analysis in the new millennium. Communication Monographs, 76(4), 408-420. https://doi. org $/ 10.1080 / 03637750903310360$

Henri, J.-F. (2006). Management control systems and strategy: A resource-based perspective. Accounting, Organizations and Society, 31(6), 529-558. https://doi. org/10.1016/j.aos.2005.07.001

Henseler, J., Ringle, C.M., \& Sarstedt, M. (2015). A new criterion for assessing discriminant validity in variance-based structural equation modeling. Journal of the Academy of Marketing Science, 43(1), 115-135. https://doi.org/10.1007/s11747-0140403-8

Henseler, J., Ringle, C., \& Sinkovics, R. (2009). The use of partial least squares path modeling in international marketing. Advances in International Marketing (AIM), 20, 277-320. https://doi.org/10.1108/S1474-7979(2009)0000020014

Huang, H.-C., Lai, M.-C., Kao, M.-C., \& Sung, C.-H. (2014). A team-learning framework for business model innovation in an emerging market. Journal of Management \& Organization, 20(1), 100-120. https://doi.org/10.1017/jmo.2014.20

Hull, F.M. (2003). Product development in service enterprises: Case studies of good practice. In J. Tidd \& F.M. Hull (Eds.), Service innovation: Organizational responses to technological opportunities \& market imperatives (pp. 371-390). United Kingdom: Imperial College Press. https://doi.org/10.1142/9781848161306_0014

Hull, F.M. (2004). Innovation strategy and the impact of a composite model of service product development on performance. Journal of Service Research, 7(2), 167180. https://doi.org/10.1177/1094670504268452

Hull, F.M., \& Tidd, J. (2003a). A composite framework of product development and delivery effectiveness in services. In J. Tidd \& F.M. Hull (Eds.), Service innovation: Organization responses to technological opportunities \& market imperatives (vol. 9, pp. 343-371). United Kingdom: Imperial College Press. https://doi. org/10.1142/9781848161306_0013 
Hull, F.M., \& Tidd, J. (2003b). The organization of new service development in the USA and UK. In J. Tidd \& F. Hull (Eds.), Service innovation: Organization responses to technological opportunities \& market imperatives (vol. 9, pp. 137-174). United Kingdom: Imperial College Press. https://doi.org/10.1142/9781848161306_0006

Hultink, E.J., Griffin, A., Hart, S., \& Robben, H.S. (1997). Industrial new product launch strategies and product development performance. Journal of Product Innovation Management, 14(4), 243-257. https://doi.org/10.1111/1540-5885.1440243

Indounas, K. (2006). Making effective pricing decisions. Business Horizons, 49(5), 415424. https://doi.org/10.1016/j.bushor.2006.02.003

Ingenbleek, P., Debruyne, M., Frambach, R.T., \& Verhallen, T.M.M. (2003). Successful new product pricing practices: A contingency approach. Marketing Letters, 14(4), 289-305. https://doi.org/10.1023/B:MARK.0000012473.92160.3d

Ingenbleek, P., Frambach, R.T., \& Verhallen, T.M.M. (2010). The role of value-informed pricing in market-oriented product innovation management. Journal of Product Innovation Management, 27(7), 1032-1046. https://doi.org/10.1111/j.15405885.2010.00769.x

Jiménez-Jiménez, D., \& Sanz-Valle, R. (2011). Innovation, organizational learning, and performance. Journal of Business Research, 64(4), 408-417. https://doi. org/10.1016/j.jbusres.2010.09.010

Klein, E.E., \& Dologite, D.G. (2000). The role of computer support tools and gender composition in innovative information system idea generation by small groups. Computers in Human Behavior, 16(2), 111-139. https://doi.org/10.1016/S07475632(00)00013-3

Kline, R.B. (2015). Principles and practice of structural equation modeling (4th ed.). New York: Guilford Publications.

Kotelnikov, V. (2001). Innovation: The key to success. Retrieved 17 November 2017 from http://www.1000ventures.com/business_guide/crosscuttings/cross-functional_ teams.html

Liker, J.K., Collins, P.D., \& Hull, F.M. (1999). Flexibility and standardization: Test of a contingency model of product design-manufacturing integration. Journal of Product Innovation Management, 16(3), 248-267. https://doi.org/10.1111/15405885.1630248

Liozu, S.M., Hinterhuber, A., Boland, R., \& Perelli, S. (2012). The conceptualization of value-based pricing in industrial firms. Journal of Revenue \& Pricing Management, 11(1), 12-34. https://doi.org/10.1057/rpm.2011.34

Lohmöller, J.-B. (1989). Latent variable path modeling with partial least squares. Heidelberg: Physica-Verlag Heidelberg. https://doi.org/10.1007/978-3-64252512-4

Maier, F.H. (1998). New product diffusion models in innovation management: A system dynamics perspective. System Dynamics Review, 14(4), 285-308. https://doi. org/10.1002/(SICI)1099-1727(199824)14:4<285::AID-SDR153>3.0.CO;2-F

Milling, P., \& Maier, F. (1994). The impact of pricing strategies on innovation diffusion and R\&D performance. System Dynamics: An International Journal of Policy Modelling, 6, 27-35. 
Mudrak, T., van Wagenberg, A., \& Wubben, E. (2005). Innovation process and innovativeness of facility management organizations. Facilities, 23(3/4), 103118. https://doi.org/10.1108/02632770510578485

Nagle, T., Hogan, J., \& Zale, J. (2010). The strategy and tactics of pricing (5th ed.). New Jersey: Prentice Hall.

Oliver, R.L., Rust, R.T., \& Varki, S. (1997). Customer delight: Foundations, findings, and managerial insight. Journal of Retailing, 73(3), 311-336. https://doi.org/10.1016/ S0022-4359(97)90021-X

Ottenbacher, M.C. (2007). Innovation management in the hospitality industry: Different strategies for achieving success. Journal of Hospitality \& Tourism Research, 31(4), 431-454. https://doi.org/10.1177/1096348007302352

Owen, A., \& Trzepacz, D. (2002). Menu costs, firm strategy, and price rigidity. Economics Letters, 76(3), 345-349. https://doi.org/10.1016/S0165-1765(02)00055-1

Panesar, S.S., \& Markeset, T. (2008). Development of a framework for industrial service innovation management and coordination. Journal of Quality in Maintenance Engineering, 14(2), 177-193. https://doi.org/10.1108/13552510810877674

Podsakoff, P.M., MacKenzie, S.B., Lee, J.-Y., \& Podsakoff, N.P. (2003). Common method biases in behavioral research: A critical review of the literature and recommended remedies. Journal of Applied Psychology, 88(5), 879-903. https:// doi.org/10.1037/0021-9010.88.5.879

Preacher, K.J., \& Hayes, A.F. (2008). Asymptotic and resampling strategies for assessing and comparing indirect effects in multiple mediator models. Behavior Research Methods, 40(3), 879-891. https://doi.org/10.3758/BRM.40.3.879

Rahman, S.A., Taghizadeh, S.K., Ramayah, T., \& Ahmad, N.H. (2015). Service innovation management practices in the telecommunications industry: What does cross country analysis reveal? SpringerPlus, 4(1), 1-25. https://doi.org/10.1186/ s40064-015-1580-8

Segarra-Blasco, A. (2010). Innovation and productivity in manufacturing and service firms in Catalonia: A regional approach. Economics of Innovation and New Technology, 19(3), 233-258. https://doi.org/10.1080/10438590802469594

Sekaran, U., \& Bougie, R. (2010). Research methods for business: A skill building approach (5th ed.). United Kingdom: John Wiley and Sons.

Sin, L.Y.M., Tse, A.C.B., Heung, V.C.S., \& Yim, F.H.K. (2005). An analysis of the relationship between market orientation and business performance in the hotel industry. International Journal of Hospitality Management, 24(4), 555-577. https://doi.org/10.1016/j.ijhm.2004.11.002

Slater, S.F. (1995). Issues in conducting marketing strategy research. Journal of Strategic Marketing, 3(4), 257-270. https://doi.org/10.1080/09652549500000016

Taghizadeh, S.K., Jayaraman, K., Ismail, I., \& Rahman, S.A. (2014a). A study of service innovation management in the Malaysian telecommunications industry. Global Business and Organizational Excellence, 34(1), 67-77. https://doi.org/10.1002/ joe. 21585

Taghizadeh, S.K., Jayaraman, K., Ismail, I., \& Rahman, S.A. (2014b). Innovation value chain as predictors for innovation strategy in Malaysian telecommunication industry. Problems and Perspectives in Management, 12(4), 533-539. 
Taghizadeh, S.K., Jayaraman, K., Ismail, I., Rahman, S.A. (2016). Scale development and validation for DART model of value co-creation process on innovation strategy. Journal of Business \& Industrial Marketing, 31(1), 24-35. https://doi. org/10.1108/JBIM-02-2014-0033

Taghizadeh, S.K., \& Rahman, S.A. (2013). The effect of service product innovation management on market performance through organizational culture: In context of service product industry. International Journal of Business and Innovation, 1(1), 1-15.

Teece, D.J., Pisano, G., \& Shuen, A. (1997). Dynamic capabilities and strategic management. Strategic Management Journal, 18(7), 509-533. https://doi. org/10.1002/(SICI)1097-0266(199708)18:7<509::AID-SMJ882>3.0.CO;2-Z

Tidd, J., \& Bessant, J. (2009). Managing innovation: Integrating technological, market and organizational change (4th ed.). West Sussex, UK: John Wiley \& Sons, Ltd. https://doi.org/10.1142/S1363919609002480 and https://doi.org/10.1142/S1363919609002315

Tidd, J., Bessant, J., \& Pavitt, K. (2001). Managing innovation: Integrating technological, market and organizational change (2nd ed.). Chichester: John Wiley \& Sons, Ltd.

Tidd, J., Bessant, J., \& Pavitt, K. (2005). Managing innovation: Integrating technological, market and organizational change (3rd ed.). West Sussex, UK: John Wiley \& Sons, Ltd.

Toivonen, M., \& Tuominen, T. (2009). Emergence of innovations in services. The Service Industries Journal, 29(7), 887-902. https://doi.org/10.1080/02642060902749492

Van Riel, A.C.R. (2005). Introduction to the special issue on service innovation management. Managing Service Quality, 15(6), 493-495. https://doi. org/10.1108/09604520510633989

Van Riel, A.C.R., Calabretta, G., Driessen, P.H., Hillebrand, B., Humphreys, A., Krafft, M., \& Beckers, S.F. (2013). Consumer perceptions of service constellations: Implications for service innovation. Journal of Service Management, 24(3), 314329. https://doi.org/10.1108/09564231311327012

Vandermerwe, S. (2003). Getting "Customer Lock On" through innovation in services. In J. Tidd \& F.M. Hull (Eds.), Service innovation: Organizational responses to technological opportunities and market imperatives. (pp. 55-80). United Kingdom: Imperial College Press. https://doi.org/10.1142/9781848161306_0003

Wang, Q., Voss, C., Zhao, X., \& Wang, Z. (2015). Modes of service innovation: A typology. Industrial Management \& Data Systems, 115(7), 1358-1382. https:// doi.org/10.1108/IMDS-03-2015-0067 